\title{
Marker Trait Correlation Study for Fusarium wilt Resistance in Chickpea (Cicer arietinum)
}

\author{
Vishal L. Bagde*, S.J. Gahukar and A.A. Akhare
}

Centre of excellence in Plant Biotechnology, Dr. Panjabrao Deshmukh Krushi Vidyapeeth, Akola - 444104, Maharashtra, India

*Corresponding author

\begin{abstract}
A B S T R A C T
The investigation was focused on transfer of the Fusarium wilt resistance into elite cultivar. Screening of chickpea parents (ICC 506 EB and Vijay), 196 RIL's (Obtained

\section{Keywords}

Fusarium wilt, SSR, RIL's, F $\mathrm{BC}_{1} \mathrm{~F}_{1}$, MAS, PIC

Article Info

Accepted:

15 October 2018

Available Online:

10 November 2018 from ICRISAT, Hyderabad), $\mathrm{F}_{2}$ and $\mathrm{BC}_{1} \mathrm{~F}_{1}$ populations for Fusarium wilt resistance were done by Pot culture method and wilt sick plot method. The $\mathrm{BC}_{1} \mathrm{~F}_{1}$ segregated in 1:1 ratio for resistance and susceptibility and $\mathrm{F}_{2}$ progenies segregated in a ratio of 1 resistant and 3 susceptible. The RILs closely fit a 1:1 segregation ratio for resistance and susceptibility indicating that resistance to Fusarium wilt was monogenic with the recessive allele conferring resistance to Fusarium wilt in this population. The parents were screened with 43 SSR primers. 22 markers were identified polymorphic. The polymorphism ranged from 57.14 to 100.00 per cent. The PIC scores of SSR markers ranged between 0.0371 and 0.9226. The $\mathrm{BC}_{1} \mathrm{~F}_{1}$ population screened with three polymorphic foreground markers (TR19, TA110 and GA16) and four polymorphic background markers (TS82, TA194, TA135 and TA 22). The reported markers linked to susceptibility and resistance proved their effectiveness and further can be exploited for maker assisted selection (MAS) of Fusarium wilt resistance breeding in chickpea.
\end{abstract}

\section{Introduction}

Chickpea (Cicer arietinum) is third most important grain legume crop grown in the arid and semi-arid regions of the world. It is one of the important grain legume crops of India which plays an important role in food security and balanced diet.

Chickpea holds prestigious position among all legume crops because it plays an important role in food security and balanced diet. It is virtually an indispensable item in the kitchen and is considered as "king of pulses" (Bhatt and Patel, 2001). Two main types of chickpea cultivars are grown globally- kabuli and desi, representing two diverse gene pools (Pundir $e t$ al., 1985). It serves as an important source of protein in human diet and plays an important role in the enrichment of soil fertility. Chickpea seeds containing 20-30\% protein, about $40 \%$ carbohydrates, $3-6 \%$ oil, $6 \%$ crude fiber and 3\% ash (Gil et al., 1996).

Among the biotic stresses that affect chickpea (Cicer arietinum), Fusarium wilt (Fusirium 
oxysporum) is a major yield-limiting factor. Fusarium wilt is a soilborne disease that causes severe yield losses. The pathogen is both seed and soil borne, survives in the soil for more than six years in the absence of susceptible host plants (Haware et al., 1986).

Eight physiological races of the pathogen (race $0,1 \mathrm{~A}, 1 \mathrm{~B} / \mathrm{C}, 2,3,4,5$ and 6 ) have been identified by reaction on set of differential chickpea cultivars (Jimenez-Diaz et al., 1989). Races 0 and 1B/C induce yellowing symptoms, whereas remaining races inducing wilting.

The use of DNA-based markers for the genetic analysis and manipulation of important agronomic traits has become an increasingly useful tool in plant breeding. Marker-assisted selection (MAS) is a new paradigm in plant breeding. Although chickpea improvement for Fusarium wilt resistance through conventional breeding and hybrid technology is ongoing, molecular breeding should accelerate utilization of the substantial variability among the chickpea landraces and germplasm lines. The application of biotechnology would be a better choice to minimize the incidence of disease and pest in agricultural crops. The use of molecular markers in crop cultivars gives an additional advantage in characterizing, selection and maintaining the genetic purity.

\section{Materials and Methods}

\section{Experimental material}

The experimental chickpea seed material for the present investigation comprised of a mapping population in the form of 196 recombinant inbred lines (RILs) derived from a cross between Vijay (resistant to Fusarium wilt) X ICC 506 EB (susceptible to Fusarium wilt). The experimental material was kindly provided by Dr. H. C. Sharma, Principle Scientist, Entomology from ICRISAT.

\section{Collection of diseased samples}

Chickpea wilt infected samples were collected from the field of Pulses Research Unit, Dr. Panjabrao Deshmukh Krishi Vidyapeeth, Akola, Maharashtra. The samples were collected during chickpea growing season in the year 2012-2013.

\section{Preparation of Mass inoculums}

Purified cultures of six isolates of Fusarium oxysporum f. sp. ciceri were mass multiplied separately on sorghum sand medium (1 part partially broken sorghum grain +3 part sand + distilled water to moisten the media). The media was prepared by mixing broken sorghum grains with clean sand in plastic tub followed by moistening with distilled water. About $500 \mathrm{~g}$ mixture was transferred in 2000 $\mathrm{ml}$ Erlenmayer flask plugged using non absorbent cotton and sterilized in an autoclave at 15 p.s.i. for 30 minutes consequently for two days.

It was allowed to cool and the flasks containing the sterilized media were inoculated with mycelial disc of pure culture of $F$. oxysporum f. sp. ciceri ( $5 \mathrm{~mm}$ diameter) and incubated at $27 \pm 2{ }^{\circ} \mathrm{C}$ for 15 days. Sufficient quantity of inoculum was prepared and used for preparing sick pots required in pot experiments.

\section{Preparation of sick soil}

Soil was collected in gunny bags and sterilized in autoclave at $1.05 \mathrm{~kg} / \mathrm{cm}^{2}$ for one hour consequently for three days. Sand was added to the soil to facilitate proper drainage and aeration in pots.

Finally the mass multiplied fungus inoculum was added in 1: 10 proportion to soil and thoroughly mixed, thus the soil was made sick. 


\section{Pathogenicity test}

Plastic pots of size $10 \mathrm{~cm}$ diameter were taken and surface sterilized with $0.1 \% \mathrm{HgCl}_{2}$. The sick soil was filled in sterilized pots $1 / 4^{\text {th }}$ of its capacity. The pots were given water lightly and incubated for 4 days. Five seeds of susceptible chickpea cultivar JG-62 were surface disinfected with $4 \%$ sodium hypochlorite solution for 30 seconds and sown in pots each isolate in 3 replications. The seedlings maintained in sterilized soil without inoculums were served as control. Plants were observed periodically upto 30 days after sowing (DAS) for wilt symptoms and disease incidence (\%) and total mortality was calculated. Different isolates of $F$. oxysporum were tested by sick soil method for their virulence on susceptible variety JG-62. The percent wilting was recorded on the basis of healthy and wilted plants. Wilt incidence was calculated by using formula,

The isolates of Fusarium oxysporum f. sp. ciceri were tentatively divided into three groups on the basis of virulence as Non pathogenic isolates (0-10 percent), Moderately pathogenic isolates(10.1-30 percent), Highly pathogenic isolates $(>30$ percent $)$

\section{Screening of chickpea parents and RIL's by Pot culture method}

Screening of chickpea parents (ICC-506 and Vijay) and 196 RIL's (Obtained from ICRISAT, Hyderabad) for wilt resistance were done by Pot culture method in green house. Plastic pots of size $10 \mathrm{~cm}$ diameter were taken and surface sterilized with $0.1 \% \mathrm{HgCl}_{2}$. The sick soil was filled in sterilized pots upto $1 / 4^{\text {th }}$ of its capacity. The pots were watered lightly and incubated for 4 days. Chickpea seeds of parents (ICC 506 and Vijay) and 196 RIL's of susceptible chickpea cultivar JG-62 were surface disinfected with $4 \%$ sodium hypochlorite solution for 30 seconds and sown in pots in 3 replications (10 seeds per pot). The seedlings maintained in sterilized soil without inoculums were served as control. Plants were observed periodically upto 30 days after sowing (DAS) for wilt symptoms and disease incidence (percent) and total mortality were calculated. Reactions were graded as resistant (0-10 percent wilt), moderately resistant (10.1 to 30 percent wilt) and susceptible (> 30 percent wilt) (Anonymous, 2016).

\section{Screening of chickpea genotypes in Field}

Chickpea parents (ICC 506 and Vijay) and 196 RIL's (Obtained from ICRISAT, Hyderabad) were screened in wilt sick plot condition at Pulses Research Unit, Dr. PDKV, Akola. A field screening technique for wilt screening developed at ICRISAT was adopted in the present studies (Nene et al., 1980). In this screening technique a wilt susceptible check (JG-62) was sown intermittently after every five test entries so as to monitor the disease pressure. Sowing of chickpea germplasm was completed in November, 2012 with two replications of row length $3 \mathrm{~m}$ at $30 \times 10 \mathrm{~cm}$ spacing. The seed emergence was recorded 18 days after sowing. Observation on number of plants wilted was recorded at 30 days and 60 days after sowing. The percent wilt incidence was calculated on the basis of initial plant count and total number of wilted plants in each genotype and graded as follows (Anonymous, 2016).

\section{Crossing of selected genotypes}

Crossing chickpea is tedious and time consuming and a crossed pod generally produces only one seed. Emasculation is required for artificial hybridization in chickpea. The crossing programme was carried out at experimental field, Pulses Research Unit, Dr. Panjabrao Deshmukh Krishi Vidyapeeth, Akola during rabi 2012- 
2013 to 2014-2015. The crosses were made during rabi 2012-2013, to obtain first filial $\left(F_{1}\right)$ generation. The $F_{1}$ was grown to produce $F_{2}$ population. The $F_{1}$ 's were crossed with above female to produce $\mathrm{BC}_{1} \mathrm{~F}_{1}$ backcross populations during rabi 2013-2014. All these populations viz., $\mathrm{P} 1, \mathrm{P} 2, \mathrm{~F} 1, \mathrm{BC}_{1} \mathrm{~F}_{1}$ were sown in rabi 2014-2015.

\section{Parental polymorphism study}

The parents of the mapping population ICC 506 EB and Vijay were screened with 43 SSR markers for identification of the polymorphic markers.

Polymorphism study of RIL's using polymorphic markers

The mapping population derived from ICC 506 EB and Vijay was screened with 22 SSR (Table 1) markers which were found polymorphic between parents. The data generated from polymorphism of RIL's was used for further analysis.

\section{Methodology for SSR Markers}

For SSR marker studies, genomic DNA was isolated from each of the parent and 196 RILs using a modified CTAB method (Sharma et al., 2002). Forty three SSR primer pairs were used for the present investigation. The sequence information for these primers was obtained from reviewed literature, while the synthesis was done from Genaxy Scientific Pvt. Ltd., India.

\section{Scoring of SSR amplified bands and genotyping}

The polymorphic SSR markers identified to be polymorphic after parental polymorphism analysis were utilized further for the molecular data scoring to know the genotyping of the 196 RILs based on morphological data and the parents. The gel image of SSR analysis were captured and visualizaed under light in gel documentation system (Biorad). Data was scored as the presence (1) or absence (0) of individual band for each isolate. The similarity index was calculated and the data was used to generate similarity coefficient using simple matching coefficient based on SSR bands scoring. The similarity coefficient between each pair of accessions were then used to construct a dendrogram using the Unweighted Pair Group Method with Arithmetic Average (UPGMA)

\section{Results and Discussion}

Chickpea wilt infected samples were collected from the field of Pulses Research Unit, Dr. Panjabrao Deshmukh Krishi Vidyapeeth, Akola, Maharashtra during chickpea growing season in the year 2012-2013.The tissue isolation method was used for isolation of Fusarium oxysporum f.sp. ciceri from infected plants showing typical wilt symptoms. The pure culture thus obtained was identified as Fusarium oxysporum f.sp. ciceri on the basis of morphological characters reported by Booth (1977) (Plate 1).

The Pathogenicity test of isolates of $F$. oxysporum f.sp. ciceri isolated was tested by using susceptible cultivar JG-62.The samples of Fusarium oxysporum f. sp. ciceri, proved to be pathogenic to susceptible cultivar JG-62 (64.28\%). The isolate from Pulses Research Unit, Dr. Panjabrao Deshmukh Krishi Vidyapeeth, Akola, Maharashtra were used for further screening of parents and RIL population.

Screening of chickpea parents (ICC 506 EB and Vijay) and 196 RIL's (Obtained from ICRISAT, Hyderabad) for wilt resistance were done by Pot culture method (Fig. 1) in green house as well as in wilt sick plot condition (Fig. 2) at Pulses Research Unit, Dr. PDKV, 
Akola. A field screening technique for wilt screening developed at ICRISAT was adopted in the present studies (Nene et al., 1991). JG62 a highly susceptible genotype was used as a check.

Among the 196 RILs, 22 RILs were resistant, 55 RILs were moderately resistant and 119 were susceptible. The RILs also segregated in 1:1 ratio for resistance and susceptibility, indicating that resistance to Fusarium wilt was monogenic in this population. The details of the experiment are given in Table 2 (Plate 2, 3 and 4).

The crossing programme was carried out at experimental field, Pulses Research Unit, Dr. Panjabrao Deshmukh Krishi Vidyapeeth, Akola. Total 310 flowers were pollinated to obtain $F_{1}$ and 260 flowers were pollinated to obtain $\mathrm{BC}_{1} \mathrm{~F}_{1}$. Percent pod set observed for $\mathrm{F}_{1}$ was $20.64 \%$ and for $\mathrm{BC}_{1} \mathrm{~F}_{1}, \%$ pod set was $18.64 \%$ (Table 3).

Screening of parents (Vijay and ICC 506 EB), $\mathrm{BC}_{1} \mathrm{~F}_{1}$ and $\mathrm{F}_{2}$ generations for wilt resistance were done by Pot culture method in green house. JG-62 a highly susceptible genotype was used as a check. Among the $51 \mathrm{BC}_{1} \mathrm{~F}_{1} 26$ plants were resistant and 25 were susceptible. The susceptible parent ICC 506 EB, showed 83.33 percent wilting in 30 days after sowing, whereas Vijay was resistant till maturity. Among the $136 \mathrm{~F}_{2}, 107$ were found resistant and 29 were susceptible.

The $\mathrm{BC}_{1} \mathrm{~F}_{1}$ segregated in 1:1 ratio for resistance and susceptibility and $F_{2}$ progenies segregated in a ratio of 3 susceptible and 1 resistant. The RILs also closely fit a 1:1 segregation ratio for resistance and susceptibility indicating that resistance to Fusarium wilt was monogenic in this population. The data revealed segregation of a single gene with the recessive allele conferring resistance to Fusarium wilt (Table 4).
SSR markers were found to be useful genetic markers as revealed by their co dominance, high frequency, and high polymorphism. The parents were screened with 43 SSR primers to identify the polymorphic markers associated with Fusarium wilt resistance component traits. Out of 43 SSR markers screened, 22 polymorphic markers were identified. Genetic variation was detected among 196 RIL's using identified polymorphic SSR marker for Fusarium oxysporum f.sp. ciceri. The segregation of the 22 polymorphic markers across the mapping population (RIL) was analyzed using the PCR. The polymorphic markers were separated on 8 percent denaturing PAGE (Poly acrylamide gel electrophoresis).

All primers showed good polymorphism and produced scorable bands with high degree of polymorphism. Twenty two SSR primer pairs produced total of 92 alleles across 196 RIL's, of which 81 were found polymorphic. Maximum of 8 alleles were amplified by primer pairs of TA 200 and the least alleles 2 were amplified by CaSTMS21, TA8, CaSTMS2, CaSTMS15, TA135 and TA71 primer. Total number of alleles generated per primer pair ranged from 2 to 8 , with an average of 4.18 alleles per primer (Table 5). Twenty two SSR primer pairs produced total of 92 alleles across 196 RIL's, of which 81 were found polymorphic. The extent of polymorphism ranged from 57.14 per cent (TA103) to 100.00 per cent with an average of 91.97 per cent. The size of amplified alleles ranged between 114-300 bp. Genetic diversity for a specific marker was evaluated by PIC. The range of PIC scores of SSR markers ranged between 0.0371 (TR19) to 0.9226 (TR1). The average PIC value of primers was observed to be 0.2294 . Results of percent polymorphism by SSR marker earlier reported by 100 percent by Singh et al., (2008), 93 percent by Datta et al., (2010), 83 percent by Rizvi et al., (2014). 
Table.1 List SSR primers revealed polymorphism among parents

\begin{tabular}{|c|c|c|}
\hline Sr. No. & Primer Name & Forward and Reverse sequence \\
\hline \multirow[t]{2}{*}{1} & \multirow[t]{2}{*}{ TR19 } & F- TCAGTATCACGTGTAATTCGT \\
\hline & & R- CATGAACATCAAGTTCTCCA \\
\hline \multirow[t]{2}{*}{2} & \multirow[t]{2}{*}{ TA 96} & F- TGTTTTGGAGAAGAGTGATTC \\
\hline & & R- TGTGCATGCAAATTCTTACT \\
\hline \multirow[t]{2}{*}{3} & \multirow[t]{2}{*}{ TA 27} & F- GATAAAATCATTATTGGGTGTCCTTT \\
\hline & & R- TTCAAATAATCTTTCATCAGTCAAATG \\
\hline \multirow[t]{2}{*}{4} & \multirow[t]{2}{*}{ TA 59} & F- ATCTAAAGAGAAATCAAAATTGTCGAA \\
\hline & & R-GCAAATGTGAAGCATGTATAGATAAAG \\
\hline \multirow[t]{2}{*}{5} & \multirow[t]{2}{*}{ TS 82} & F- TCAAGATTGATATTGATTAGATAAAAGC \\
\hline & & R- CTTTATTTACCACTTGCACAACACTAA \\
\hline \multirow[t]{2}{*}{6} & \multirow[t]{2}{*}{ TA 194} & F- TTTTTGGCTTATTAGACTGACTT \\
\hline & & R- TTGCCATAAAATACAAAATCC \\
\hline \multirow[t]{2}{*}{7} & \multirow[t]{2}{*}{ TA 110} & F- ACACTATAGGTATAGGCATTTAGGCAA \\
\hline & & R- TTCTTTATAAATATCAGACCGGAAAGA \\
\hline \multirow[t]{2}{*}{8} & \multirow[t]{2}{*}{ TA 103} & F- TGAAATATCTAATGTTGCAATTAGGAC \\
\hline & & R- TATGGATCACATCAAAGAAATAAAAT \\
\hline \multirow[t]{2}{*}{9} & \multirow[t]{2}{*}{ TA 200} & F- TTTCTCCTCTACTATTATGATCACCAG \\
\hline & & R- TTGAGAGGGTTAGAACTCATTATGTTT \\
\hline \multirow[t]{2}{*}{10} & \multirow[t]{2}{*}{ GA 16} & F- CACCTCGTACCATGGTTTCTG \\
\hline & & R- TAAATTTCATCCTCTCCGGC \\
\hline \multirow[t]{2}{*}{11} & \multirow[t]{2}{*}{ TA 37} & F- ACTTACATGAATTATCTTTCTTGGTCC \\
\hline & & R- CGTATTCAAATAATCTTTCATCAGTCA \\
\hline \multirow[t]{2}{*}{12} & \multirow[t]{2}{*}{ TA72 } & F- GAAAGATTTAAAAGATTTTCCACGTTA \\
\hline & & R-TTAGAAGCATATTGTTGGGATAAGAGT \\
\hline \multirow[t]{2}{*}{13} & TA130 & F- TCTTTCTTTGCTTCCAATGT \\
\hline & & R-GTAAATCCCACGAGAAATCAA \\
\hline 14 & TA71 & F- CGATTTAACACAAAACACAAA \\
\hline & & R-CCTATCCATTGTCATCTCGT \\
\hline 15 & TA22 & F- TCTCCAACCCTTTAGATTGA \\
\hline & & R-TCGTGTTTACTGAATGTGGA \\
\hline 16 & TA135 & F- TGGTTGGAAATTGATGTTTT \\
\hline & & R-GTGGTGTGAGCATAATTCAA \\
\hline 17 & TR1 & F- CGTATGATTTTGCCGTCTAT \\
\hline & & R-ACCTCAAGTTCTCCGAAGT \\
\hline 18 & CaSTMS2 & F- АТTTТАСТTТАСТАСТTТTТТССТTТC \\
\hline & & R-AATAAATGGAGTGTAAATTTCATGTA \\
\hline 19 & CaSTMS15 & F- CTTGTGAATTCATATTTACTTATAGAT \\
\hline & & R-ATCCGTAATTTAAGGTAGGTTAAAATA \\
\hline 20 & CaSTMS21 & F- CTACAGTCTTTTGTTCTTCTAGCTT \\
\hline & & R-ATATTTTTTAAGAGGCTTTTGGTAG \\
\hline 21 & TA8 & F- AAAATTTGCACCCACAAAATATG \\
\hline & & R-CTGAAAATTATGGCAGGGAAAC \\
\hline 22 & TA21 & F- GTACCTCGAAGATGTAGCCGATA \\
\hline & & R- TTTTCCATTTAGAGTAGGATCTTCTTG \\
\hline
\end{tabular}


Table.2 Screening of Parents and RIL populations in wilt sick pot

\begin{tabular}{|l|c|}
\hline & \% Mean wilt incidence \\
\hline Mean of RIL's & $38.60(37.93)^{*}$ \\
\hline Vijay & $10(18.43)$ \\
\hline ICC 506 EB & $83.33(66.14)$ \\
\hline JG-62 (check) & $90(90.00)$ \\
\hline SE \pm & 3.62 \\
\hline C. D. @ 5\% & 10.08 \\
\hline * - transformed values &
\end{tabular}

Table.3 Observations for cross ICC-506 $\times$ Vijay

\begin{tabular}{|l|c|c|}
\hline Crosses & $\begin{array}{c}\text { ICC 506 EB } \times \text { Vijay } \\
\left(\mathrm{F}_{1}\right)\end{array}$ & $\begin{array}{c}\mathrm{F}_{1} \times \mathrm{ICC} \mathbf{5 0 6} \mathrm{EB} \\
\left(\mathrm{BC}_{\mathbf{1}} \mathrm{F}_{1}\right)\end{array}$ \\
\hline No. of Pollinations & 310 & 260 \\
\hline No. of Pod set & 64 & 48 \\
\hline No. of seed set & 69 & 52 \\
\hline$\%$ Pod set & 20.64 & 18.64 \\
\hline
\end{tabular}

Table.4 Inheritance of wilt resistance in a cross ICC-506 x Vijay

\begin{tabular}{l|c|c|c|c|c|c|c|}
\hline & $\begin{array}{c}\text { Total } \\
\text { plants }\end{array}$ & $\begin{array}{c}\text { Wilted } \\
\text { plants }\end{array}$ & $\begin{array}{c}\text { Non wilted } \\
\text { plants }\end{array}$ & $\begin{array}{c}\text { Expected } \\
\text { ratio }\end{array}$ & df & $x^{2}$ & P-value \\
\hline RIL's & 196 & 119 & 77 & $1: 1$ & 1 & 9.433 & 0.0021 \\
\hline$F_{2}$ & 136 & 107 & 29 & $3: 1$ & 1 & 0.1985 & 0.655 \\
\hline $\mathrm{BC}_{1} \mathrm{~F}_{1}\left(\mathrm{~F}_{1} \times\right.$ & 51 & 25 & 26 & $1: 1$ & 1 & 0.078 & 0.780 \\
\hline $\mathrm{ICC} 506 \mathrm{~EB})$ & & & & & & & \\
\hline$d f=1 ; P=0.05 ; x^{2}=3.841$ & & & &
\end{tabular}


Table.5 Percentage polymorphism of different SSR primers

\begin{tabular}{|c|c|c|c|c|c|}
\hline $\begin{array}{l}\text { Sr. } \\
\text { No. }\end{array}$ & Primers & $\begin{array}{l}\text { Total no. of } \\
\text { amplicons }\end{array}$ & Polymorphic alleles & $\begin{array}{c}\text { Percentage of } \\
\text { polymorphism (\%) }\end{array}$ & PIC \\
\hline 1. & TR19 & 5 & 5 & 100.00 & 0.1883 \\
\hline 2. & TA 96 & 5 & 4 & 80.00 & 0.0994 \\
\hline 3. & TA 27 & 6 & 4 & 66.66 & 0.0371 \\
\hline 4 & TA 59 & 7 & 5 & 71.42 & 0.0713 \\
\hline 5. & TS 82 & 4 & 4 & 100.00 & 0.1775 \\
\hline 6. & TA 194 & 7 & 7 & 100.00 & 0.0702 \\
\hline 7. & TA 110 & 3 & 3 & 100.00 & 0.2332 \\
\hline 8. & TA 103 & 7 & 4 & 57.14 & 0.0681 \\
\hline 9. & GA 16 & 3 & 3 & 100.00 & 0.2769 \\
\hline 10. & TA 200 & 8 & 7 & 87.50 & 0.0601 \\
\hline 11. & TA 37 & 5 & 5 & 100.00 & 0.1911 \\
\hline 12. & TA 72 & 7 & 6 & 85.71 & 0.0687 \\
\hline 13. & TA130 & 2 & 2 & 100.00 & 0.2385 \\
\hline 14. & TA 71 & 2 & 2 & 100.00 & 0.4872 \\
\hline 15. & TA 22 & 3 & 3 & 100.00 & 0.2704 \\
\hline 16. & CaSTMS15 & 2 & 2 & 100.00 & 0.4864 \\
\hline 17. & TA135 & 2 & 2 & 100.00 & 0.4875 \\
\hline 18. & TR1 & 4 & 3 & 75.00 & 0.9226 \\
\hline 19. & CaSTMS2 & 2 & 2 & 100.00 & 0.4069 \\
\hline 20. & TA21 & 4 & 4 & 100.00 & 0.1929 \\
\hline 21. & CaSTMS21 & 2 & 2 & 100.00 & 0.4001 \\
\hline \multirow[t]{3}{*}{22.} & TA8 & 2 & 2 & 100.00 & 0.3421 \\
\hline & Total & 92 & 81 & - & - \\
\hline & Average & 4.18 & 3.68 & 91.97 & 0.2294 \\
\hline
\end{tabular}

Table.6 Foreground selection for ICC $506 \mathrm{~EB} X$ Vijay derived $\mathrm{BC}_{1} \mathrm{~F}_{1}$ progenies

\begin{tabular}{|l|l|c|}
\hline $\begin{array}{c}\text { Sr. } \\
\text { No. }\end{array}$ & \multicolumn{1}{|c|}{ Particulars } & $\begin{array}{c}\text { ICC 506 EB X } \\
\text { Vijay }\end{array}$ \\
\hline 1 & Number of plants screened & 51 \\
\hline 2 & Number of polymorphic marker used & 3 \\
\hline 3 & Scorable marker data points generated & 149 \\
\hline 4 & $\begin{array}{l}\text { Number of progeny satisfying the foreground selection for all the targeted QTL } \\
\text { regions }\end{array}$ & 8 \\
\hline 5 & Marker status of selected plants at target QTL regions & Heterozygous \\
\hline
\end{tabular}

Table.7 Background selection for ICC $506 \mathrm{~EB} X$ Vijay derived $\mathrm{BC}_{1} \mathrm{~F}_{1}$ progenies

\begin{tabular}{|l|l|c|}
\hline $\begin{array}{l}\text { Sr. } \\
\text { No. }\end{array}$ & \multicolumn{1}{|c|}{ Particulars } & $\begin{array}{c}\text { ICC 506 EB X } \\
\text { Vijay }\end{array}$ \\
\hline 1 & Number of plants screened & 51 \\
\hline 2 & Number of polymorphic marker used & 4 \\
\hline 3 & Scorable marker data points generated \\
\hline 4 & $\begin{array}{l}\text { Number of progeny satisfying the foreground selection for all the targeted QTL } \\
\text { regions }\end{array}$ & 3 \\
\hline 5 & Marker status of selected plants at target QTL regions & Heterozygous \\
\hline
\end{tabular}




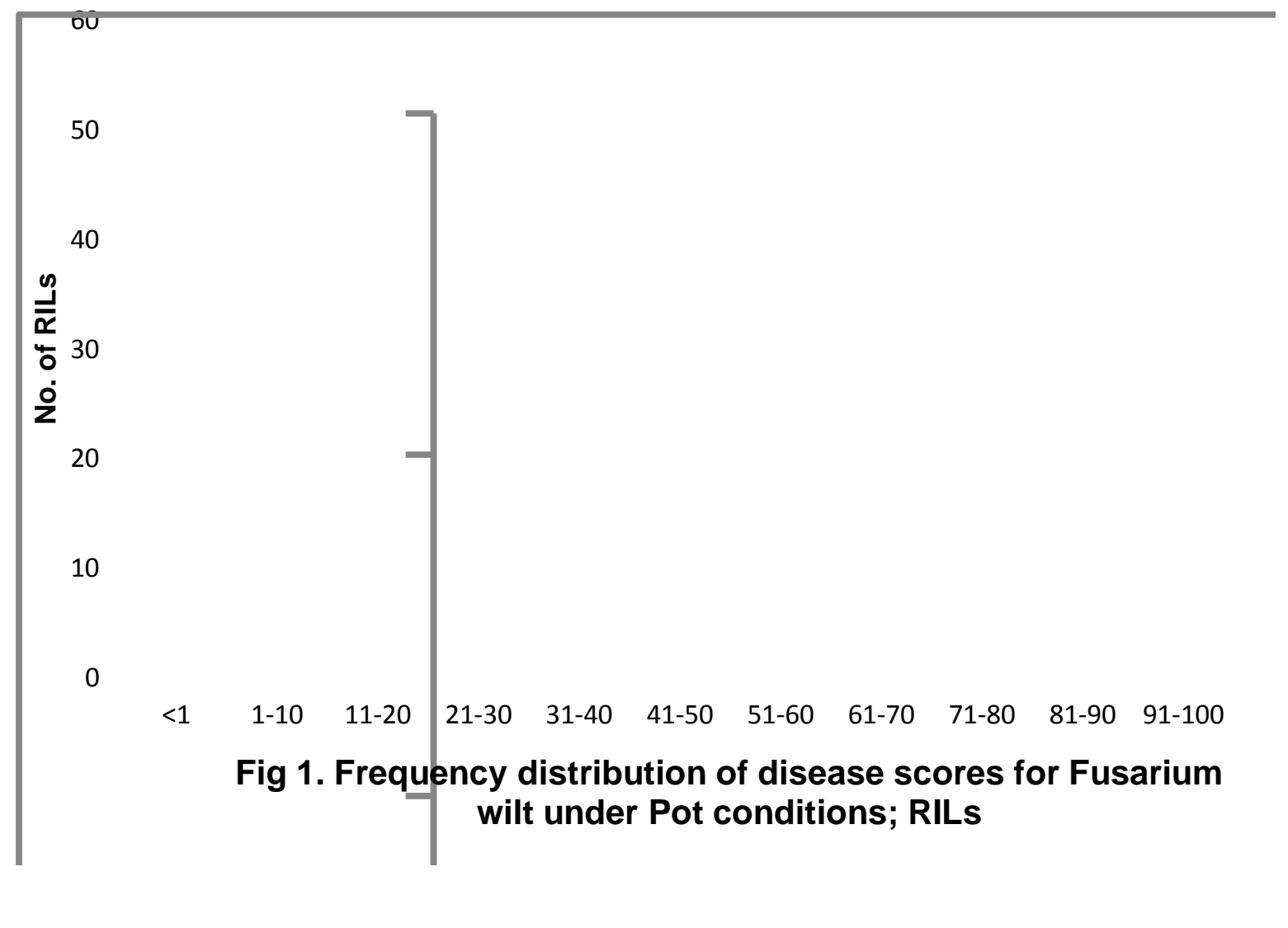

120

100

80

$\stackrel{\stackrel{9}{\vec{x}}}{\frac{4}{0}} 60$

i

40

20

0

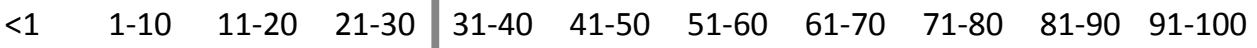

Fig 2. Frequency distribution of disease scores for Fusarium wilt under field conditions; RILs 
Int.J.Curr.Microbiol.App.Sci (2018) 7(11): 2102-2118

Fig.3 Dendrogram constructed using Jaccard's similarity coefficient and UPGMA clustering for 196 RIL's based on SSR analysis

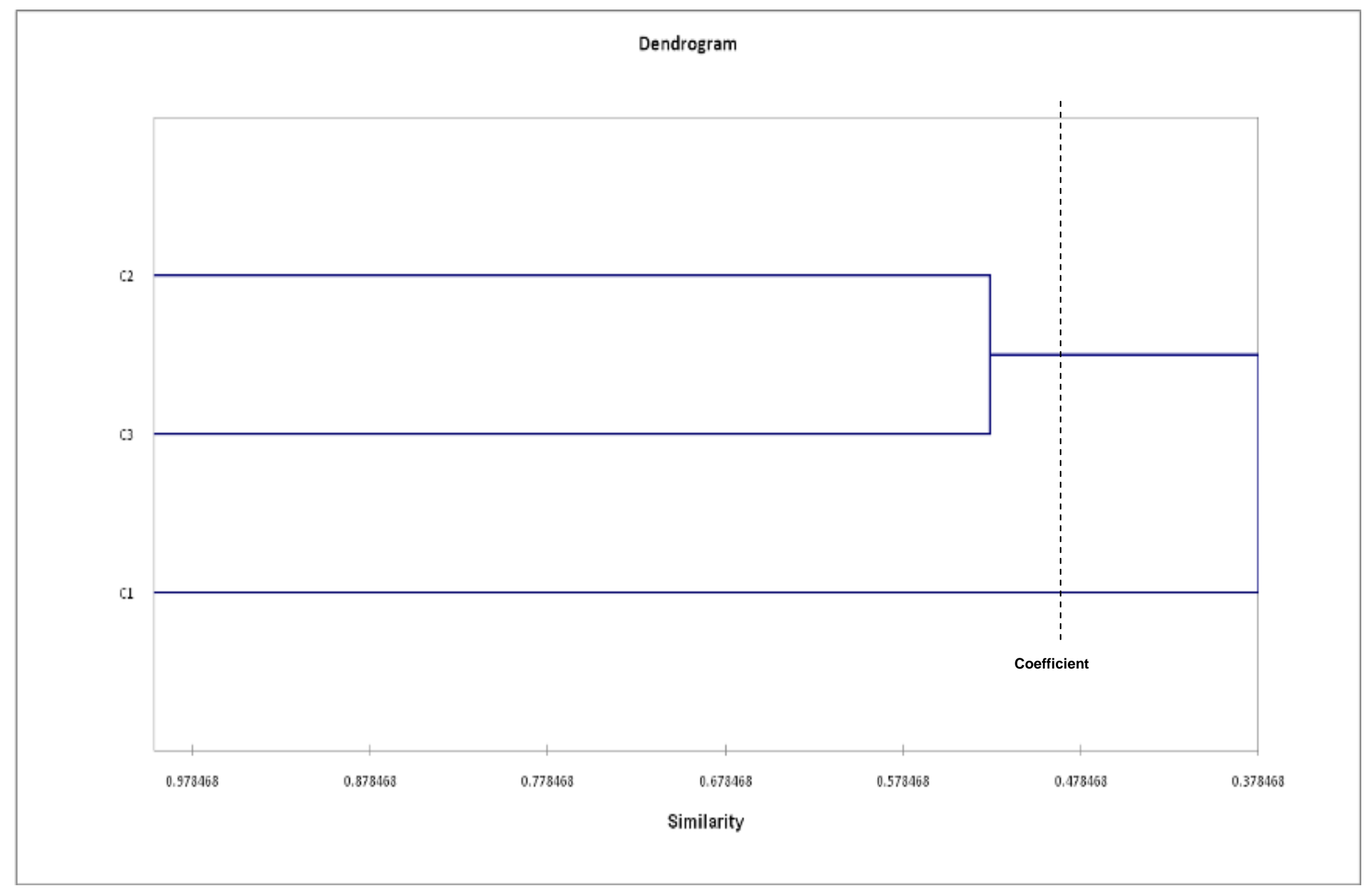


Fig.4 Dendrogram constructed using Jaccard's similarity coefficient and UPGMA clustering for 196 RIL's based on SSR analysis

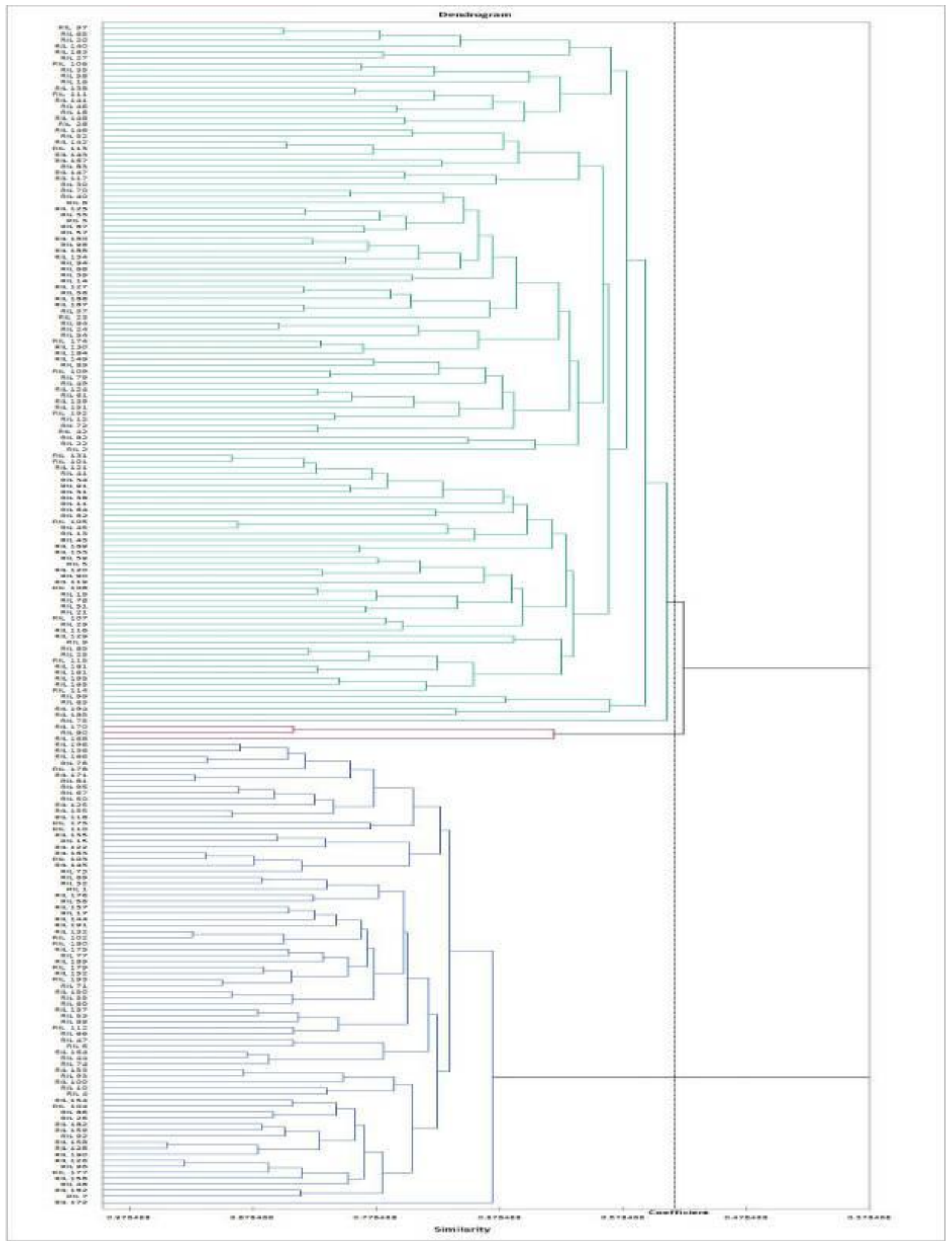



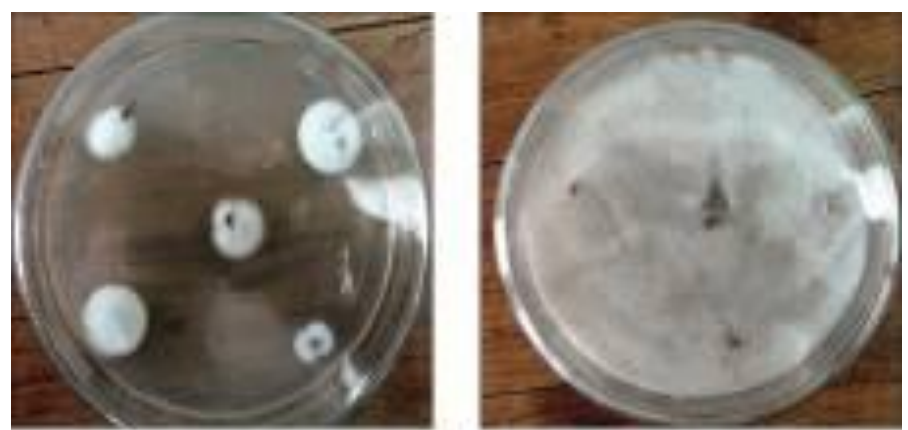

a) Isolation from infectod tissues of chickpea sosdling

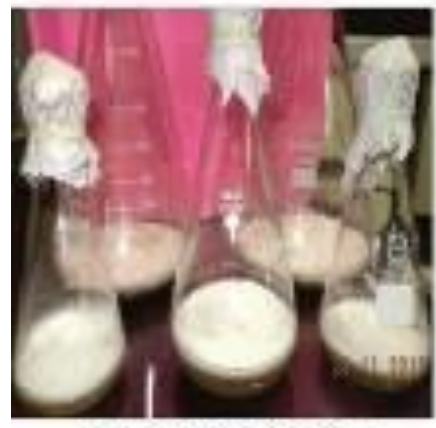

b) Qrawith on PDe broth

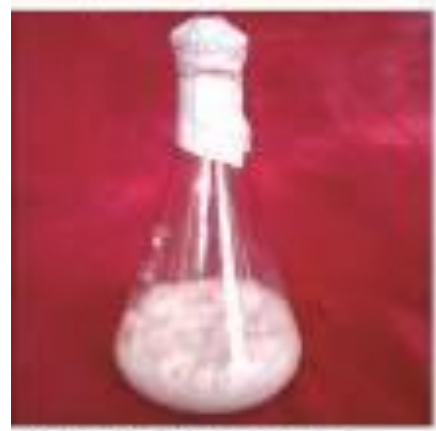

d) Growth of $F$ arysporom

f. sp. eicnri (Mnss multipliestion)

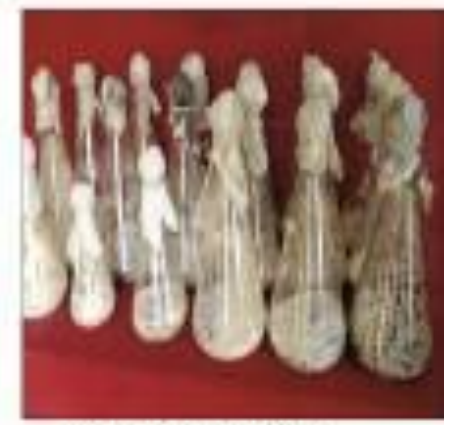

c) Mass multiplication

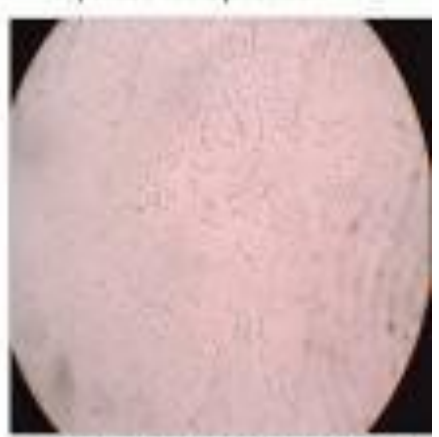

e) Nicro and macro conidla of F. oxysperew $f$, ip , elceri

Plate 1: Isolation and morphology of Fusanum oxysporum 1. sp. eicer!

Plate.2 Screening of chickpea by Pot culture method

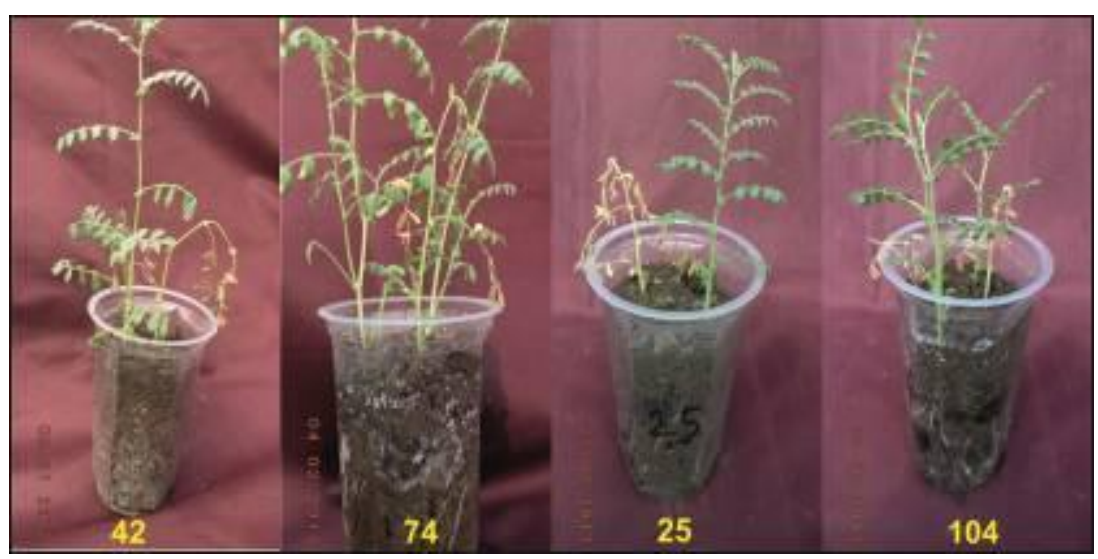


Plate.3 Screening of RIL's against Fusarium wilt by Pot culture method
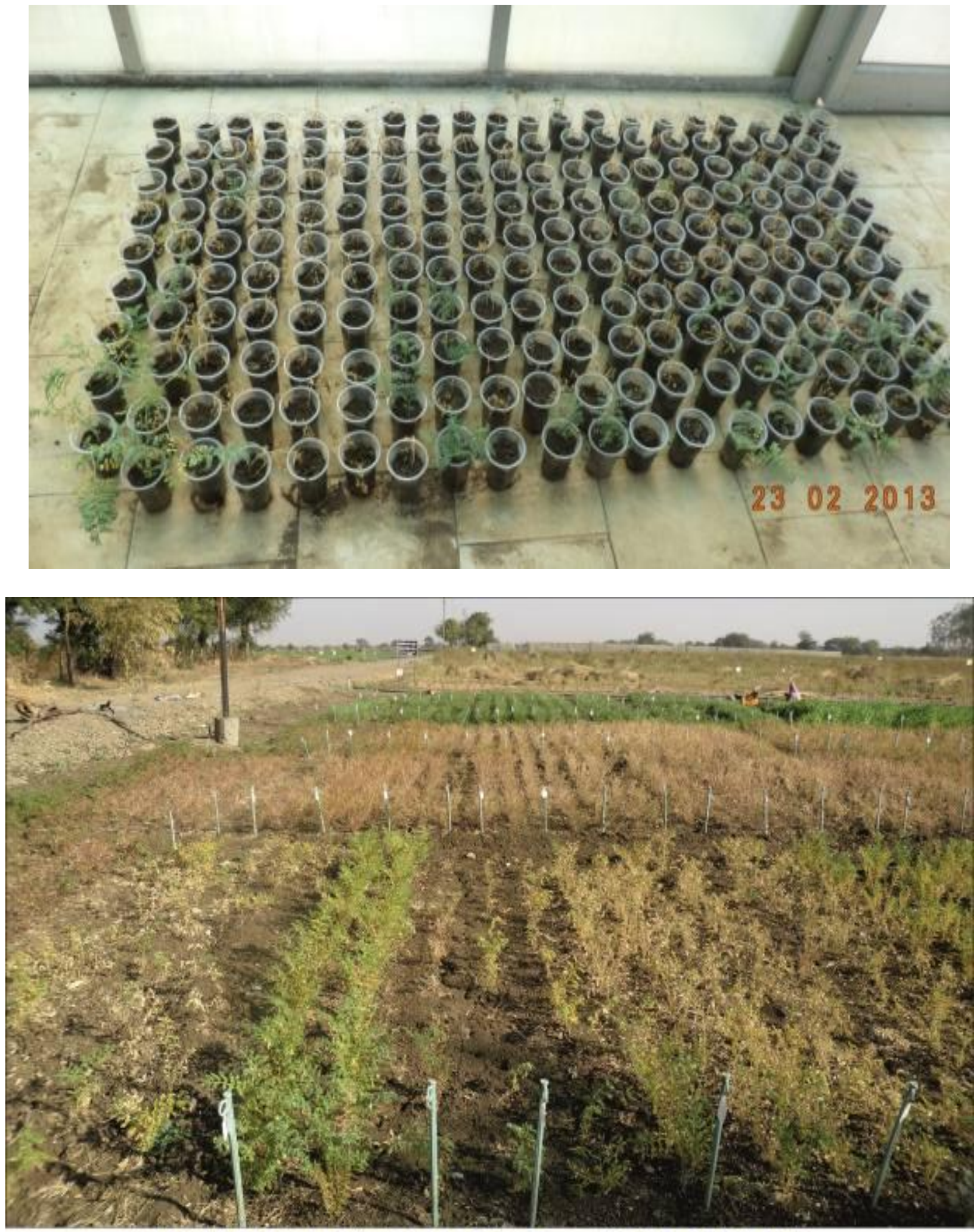

Plate 4: Field view of wilt sick plot at Pulses Research Unit, Dr. P.D.K.V., Akola. 
Int.J.Curr.Microbiol.App.Sci (2018) 7(11): 2102-2118

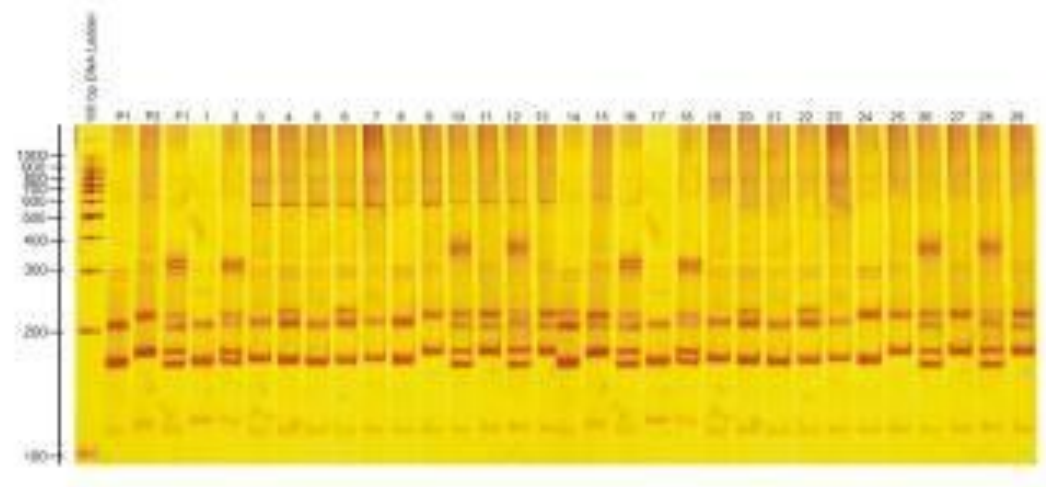

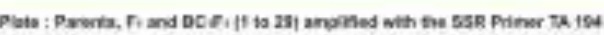

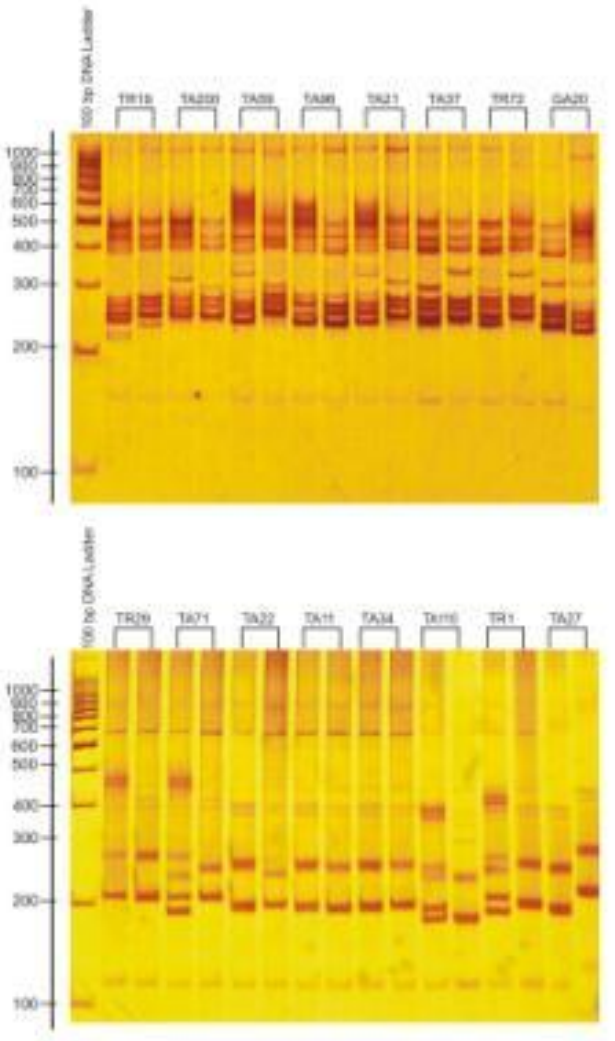
Plate 1 A photographic image showing parental gelymorphism with SSR
peimers on polyacryiamide gel 

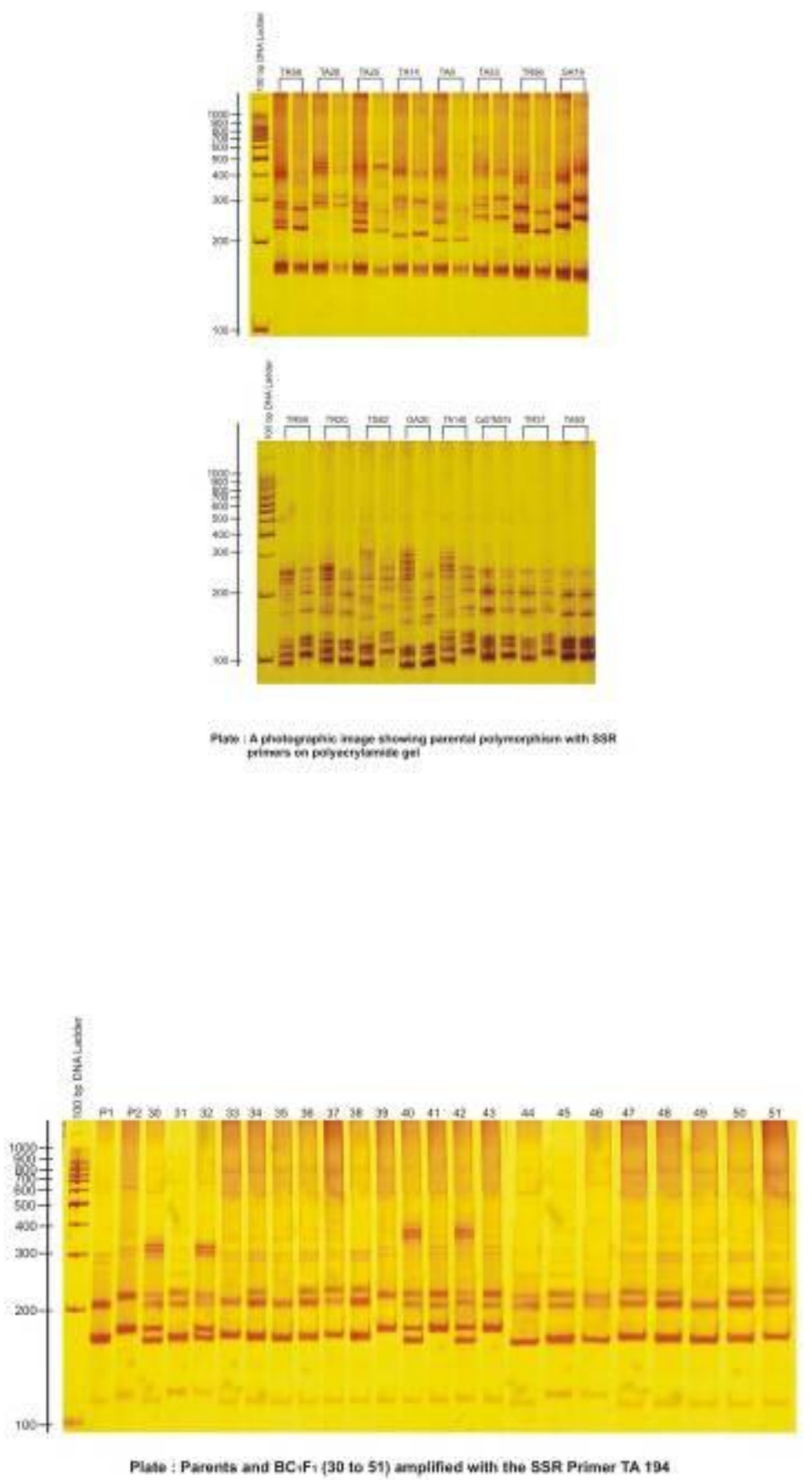

A binary similarity matrix of combined data from 22 primers for the 196 recombinant inbred lines (RILs) derived from a cross between Vijay X ICC 506 was prepared by scoring bands for presence or absence. DNA bands of same mobility (molecular weight) were assumed to be identical. The genetic similarity coefficient value ranged from 0.053 - 0.933 across the 196 recombinant inbred lines (RILs). The maximum similarity 
coefficient 0.933 was found in between two RILs 128 and 158 that were resistant for Fusarium wilt indicated less genetic diversity and more genotypic similarity. Lowest similarity coefficient 0.053 was found between 133 (susceptible) and 172 (resistant) number of RILs indicated that these RILs were less similar to each other with more genetic divergence.

Dendrogram was constructed using UPGMA method of cluster analysis based on Jaccard's similarity coefficient generated by 22 SSR primers as shown in Figure 3 and 4 . The dendrogram based on Jaccard's similarity coefficient could distinguish some sort of grouping among resistant and susceptible recombinant inbred lines (RILs).The dendrogram generated two main clusters at 53.62 per cent cut level of similarity. Cluster I $\left(\mathrm{C}_{1}\right)$ contained all 77 resistant recombinant inbred lines (RILs). Cluster II $\left(\mathrm{C}_{2}\right)$ contained 116 susceptible recombinant inbred lines (RILs) and 3 susceptible RIL's (RIL 80,168 and 170) were laid on same sub-cluster $\left(C_{3}\right)$ of cluster II. Similar findings were reported by Padaliya et al., (2013) studied six chickpea genotypes using UPGMA method.

Foreground selection for genomic regions of interest and background selection using SSR markers were employed for identification of plants for further backcrossing. Total 51 plants of the $\mathrm{BC}_{1} \mathrm{~F}_{1}$ population screened with three polymorphic foreground markers (TR19, TA110 and GA16). Out of the 51 plants, only plant no. $\mathrm{BC}_{1}-6,20,26,28,32$, 33,40 and 41 were found to be heterozygous for three primers and plant no. $\mathrm{BC}_{1}-13,17$ and 50 showed heterozygous banding pattern in two primers (Table 6).

Total 51 plants of the $\mathrm{BC}_{1} \mathrm{~F}_{1}$ population screened with four polymorphic background markers (TS82, TA194, TA135 and TA 22) for identifying the backcross progenies having recurrent parent alleles. Out of the $51 \mathrm{BC}_{1} \mathrm{~F}_{1}$ plants, only plant no. $\mathrm{BC}_{1}-20,33$ and 41 showed background of recurrent parent for all the four markers. Plant number $\mathrm{BC}_{1}-28$ showed background of recurrent parent in three primers (Table 7).

The wilt screening data from RIL's, $\mathrm{BC}_{1} \mathrm{~F}_{1}$ and $F_{2}$ revealed segregation of a single gene with the recessive allele conferring resistance to Fusarium wilt. The 22 markers identified polymorphic linked markers with Fusarium wilt resistance trait can be effectively utilized in marker assisted selection programme and aimed towards incorporating Fusarium wilt resistance in chickpea. In the present study effective population size and number of markers used for marker trait correlation for Fusarium wilt resistance were small (i.e., only 196 RILs and 20 markers). However, the results obtained can be verified with increased population size and more number of markers.

\section{References}

Anonymous, 2016. All India Coordinated Research Project, Annual report 201516 on chickpea, IIPR, Kanpur, UP, India.

Bhatt, N. J. and R. K. Patel, 2001. Screening of chickpea cultivars for their resistance to gram pod borer, Helicoverpa armigera. Indian J Entomol., 63(3): 277-280.

Datta, J., N. Lal, M. kashyap and P. P. Gupta, 2010. Efficiency of three PCR based marker systems for detecting DNA polymorphism in Cicer arientinum and Cajanus cajan L. Mills paugh. Genetic Eng. and Biotechnology J., (5):1-15.

Gil, J., S. Nadal, D. Luna, M. T. Moreno and A. De Haro, 1996. Variability of some physicochemical characters in desi and kabulli chickpea types. J Sci. of Food and Agril., (71):179-184. 
Haware, M. P., Y. L. Nene and S. B. Mathur, 1986. Seed borne diseases of chickpea. Technical Bull. No. 1. Copenhagen, Denmark: Danish Government. Institute of Seed Pathology for Developing Countries, 32.

Jimenez-Diaz, R. M., A. Trapero-Casas and C. J. Cabrera, 1989. Races of Fusarium oxysporum f.sp. ciceri infecting chickpea in southern Spain. NATOASI series, (28): 515-520.

Nene, Y. L. and M. P. Haware, 1980.Screening chickpea for resistance to wilt. Plant Dis., (64): 379-380.

Nene, Y. L., M. V. Reddy, M. P. Haware, A. M. Ghanekar and K. S. Amina, 1991. Field diagnosis of chickpea diseases and their control. In: Information Bulletin no. 28. ICRISAT. Patencheru, A.P., India: 8-10.

Padaliya, R. V., K. P. Suthar, Diwakar Singh, M. K. Mahatma and V. R. Patil, 2013.Marker assisted characterization of chickpea genotypes for wilt resistance. African J. of Biotech., 12(50): 6907-6912.

Pundir, R. P. S., N. K. Rao and L. J. G. Van Der Maesen, 1985. Distribution of qualitative traits in the world germplasm of chickpea (Cicer arietinum L.). Euphytica, (34): 697-703.

Rizvi, H., B. K. Babu, P.K. Agrawal, 2014. Molecular analysis of kabuli and desi type of Indian chickpea (Cicer arientinum L.) cultivars using STMS markers. J. Biochem. Biotech., 23(1): $52-60$.

Sharma, H. C., J. H. Crouch, K. K. Sharma, N. Seetharama and C. T. Hash, 2002. Applications of biotechnology for crop improvement: prospects and constraints. Pl. Sci., (163): 381-395.

Singh, R., P. Sharma, R. K. Varshney, S. K. Sharma and N. K. Singh, 2008. Chickpea improvement: Role of wild species and genetic markers. Biotechnol. Genet. Engg. Rev., (25): 267-314.

Varshney, R. K., R. Horres, C. Molina, S. Nayak, R. Jungmann, P. Swamy, P. Winter, B Jayashree, G. Kahl and D. A. Hoisington, 2007. Extending the repertoire of microsatellite markers for genetic linkage mapping and germplasm screening in chickpea. J. SAT Agril. Res., 5 (1):1-5.

Varshney, R. K., S. M. Mohan, P. M. Gaur, S. K. Chamarthi, V. K. Singh,S. Srinivasan, N. Swapna, M. Sharma, S. Singh, L. Kaur, and S. Pande, 2014. Marker-Assisted Backcrossing to Introgress Resistance to Fusarium wilt Race 1 and Ascochyta Blight in C 214, an Elite Cultivar of Chickpea. The Plant Genome, 7(1):1-11.

\section{How to cite this article:}

Vishal, L. Bagde, S.J. Gahukar and Akhare, A.A. 2018. Marker Trait Correlation Study for Fusarium wilt Resistance in Chickpea (Cicer arietinum). Int.J.Curr.Microbiol.App.Sci. 7(11): 2102-2118. doi: https://doi.org/10.20546/ijcmas.2018.711.236 